\title{
Efeitos da terapia hormonal na menopausa sobre o sistema imune
}

\author{
Effects of the menopause bormone therapy on the immune system
}

Palavras-chaves

Esteróides

Terapia de reposição hormona

Menopausa

Citocinas

Sistema imune

Keywords

Steroids

Hormone replacement therapy

Menopause

Cytokines

Immune system

\section{Resumo}

Existem evidências de que estrogênios, progesterona e androgênios têm efeito modulador sobre as respostas imunes humoral e celular. Estes efeitos ocorrem via interações imuno-neuroendócrinas, envolvendo a hipófise, esteróides sexuais, hormônios do timo e a presença de receptores específicos. As respostas imunes, tanto a celular como a humoral, podem ser alteradas durante a gravidez, ooforectomia, menopausa e terapia hormonal (TH). O estrogênio deprime a imunidade celular, suprime a atividade das células matadoras naturais e aumenta a produção de anticorpos. Progesterona/ progestogênios têm efeito imunossupressor sobre a imunidade celular. Androgênios, após a conversão em estrogênios, podem estimular o sistema imuno humoral. A TH é, ainda, amplamente usada em mulheres após a menopausa, com o propósito de eliminar os sintomas do hipoestrogenismo e prevenir atrofia genital e perda da massa óssea. Seu uso, com o objetivo de atenuar o risco de doenças cardiovasculares ou doenças neurodegenerativas, permanece em debate. Poucos estudos foram efetuados com o propósito de examinar o efeito da TH na pós-menopausa sobre o sistema imunológico e as reações inflamatórias. Há evidências de que o hipoestrogenismo, seguindo a menopausa, possa resultar em menor resistência às infecções. Esta revisão fundamenta o entendimento da interação entre esteróides sexuais e sistema imune e, baseado em estudos epidemiológicos e clínicos, examina a aplicabilidade da TH, durante a menopausa, na modulação das respostas imunes celular e humoral. Concluiu-se que a TH normaliza a resposta imunocelular.

\section{Abstract}

There is evidence that estrogen, progesterone and testosterone have modulatory effects over both cellular and humoral immune responses. These effects occur via immune-neuroendocrine interactions, involving the pituitary, gonadal steroids, thymic hormones, and the presence of specific receptors and messengers. These immune responses may be altered during pregnancy, gonadectomy, menopause and hormone therapy. Estrogen depresses the cellular immunity, suppresses the natural killer cell activity and increases the production of antibodies. Progesterone/progestogen suppresses the cellular immune system. Androgens, after metabolization in estrogens, might stimulate the humoral immune response. Hormone therapy is still broadly used in post-menopause women with the purpose of decreasing climacteric symptoms, as well as preventing genital atrophy and bone loss. Its use to attenuate the risk of cardiovascular and neurodegenerative diseases remains in debate. A few studies have been carried out to examine the effect of post-menopause hormone therapy on the immune system. There is evidence that the hypoestrogenic state, following menopause, could result in less resistance to infections. The present review examines the interaction between sexual steroids and the immune system and, based on epidemiological and clinical studies, evaluates the effects of hormone therapy on the immune responses. It was concluded that the hormone therapy normalizes the cellular immune response in post-menopausal women.

Correspondência: Sebastião Freitas de Medeiros Rua Marechal Deodoro, 1055, apto. 1302 CEP 78005-101 - Cuiabá/MT

Fone: $55653322-7342$

Fax: $55653623-0079$ E-mail: de.medeiros@terra.com.br

Recebido

\section{Apoio financeiro: Fundação de Apoio à Pesquisa do Estado de Mato Grosso (Fapemat).}

Professor Adjunto do Departamento de Ginecologia e Obstetrícia da Faculdade de Ciências Médicas da Universidade Federal de Mato Grosso - UFMT - Cuiabá (MT), Brasil; Diretor do Instituto Tropical de Medicina Reprodutiva e Menopausa - Cuiabá (MT), Brasil. 2 Médico Contratado do Departamento de Ginecologia e Obstetrícia do Hospital Universitário Júlio Muller da Universidade Federal de Mato Grosso - UFMT - Cuiabá (MT), Brasil.

3 Bolsista do Conselho Nacional de Desenvolvimento Científico e Tecnológico (CNPq), Programa Institucional de Bolsas de Iniciação Científica (Pibic) pela Universidade Federal de Mato Grosso - UFMT - Cuiabá (MT), Brasil. 


\section{Introdução}

Sintomas vasomotores, nervosismo, diminuição da memória e fadiga são as principais manifestações clínicas do climatério e acometem cerca de $60 \%$ das mulheres nesta fase ${ }^{1}$. A atrofia urogenital e a osteoporose surgem após alguns anos. As defesas imunes naturais do organismo também são reduzidas em certa proporção por causa da fragilidade da pele e da diminuição na produção de anticorpos pelas mucosas. A imunossenescência talvez reflita alterações celulares e humorais em todo o processo de gerar resposta específica a antígenos estranhos. As modificações da resposta imune humoral com a idade incluem (1) resposta prejudicada no reconhecimento de antígenos não-próprios, (2) aumento na produção de autoanticorpos e complexos imunocirculantes, (3) diminuição na produção de interleucina 4 (IL-4), (4) aumento na secreção de interferon- $\gamma$ (IFN- $\gamma$ ) e (5) diminuição na síntese de imunoglobulinas ${ }^{2}$. A resposta imunocelular também declina com a idade e resulta em (1) reação retardada aos antígenos de memória ${ }^{3}$ e (2) declínio na função dos linfócitos $\mathrm{B}^{4}$. Tanto aumento como diminuição na relação CD4/CD8 foram descritos em seres humanos idosos. Parece não ocorrer nenhuma mudança nos macrófagos acessórios, células dendríticas ou antígeno-específico do linfócito B.

Além da idade, os esteróides sexuais também modulam as respostas imunes. Enquanto estrogênios parecem estimular as respostas imunes, os androgênios e progesterona mostram uma tendência oposta. $\mathrm{Na}$ verdade, os estrogênios têm efeitos tanto estimuladores (em doses baixas) como supressores (em altas doses) sobre a função imunológica. Receptores de estrogênio foram encontrados em certas sub-populações de linfócitos e, nestas células, podem alterar a função, reduzir a produção de fatores imunorreguladores, limitar a expressão de antígenos e diminuir a capacidade dos linfócitos de reagir com outras células 5 . Modificações no sistema imune em mulheres após a menopausa têm sido parcialmente atribuídas ao hipoestrogenismo. No entanto, a existência de associação ou não entre um determinado evento com um fator causal exige que se considere a plausibilidade biológica e a consistência clínica examinada por estudos clínico-epidemiológicos. A avaliação crítica das informações publicadas acerca do papel dos esteróides sexuais no sistema imunológico e o possível impacto da terapia hormonal (TH) após a menopausa são revisitados nesta revisão.

\section{Métodos}

Este estudo examina possíveis interações imunoendócrinas, ou mudanças no sistema imune, em conseqüência da ação dos esteróides gonadais. Examina ainda as publicações atuais neste campo e analisa as evidências de que a $\mathrm{TH}$ pode modular as respostas imunes. Posteriormente, faz uma avaliação dos dados epidemiológicos e clínicos concernentes ao uso da TH e suas repercussões no sistema imunológico da mulher após a menopausa. O estudo foi dividido em seções e examina seqüencialmente a possível interação entre os sistemas imune e endócrino, focaliza o papel dos esteróides sexuais na resposta imunológica, analisa possíveis modificações do sistema imunológico ao longo do ciclo menstrual, avalia as repercussões da menopausa/hipoestrogenismo sobre a resposta imune e revê os estudos clínico-epidemiológicos sobre as repercussões da $\mathrm{TH}$ nas imunidades celular e humoral e inflamação. Para atender a esta proposta, uma revisão extensa da literatura foi realizada. As palavras chaves usadas na busca foram "esteróides sexuais", "sistema imunológico", "terapia hormonal", "menopausa", "climatério", "imunidade celular" e "imunidade humoral'. As bases de dados SciELO e Medline/PubMed foram pesquisadas para identificar as publicações mais relevantes nos últimos dez anos. Estudos publicados há mais tempo provendo conhecimento básico e imprescindível também foram incluídos. Artigos completos e revisões submetidos e aceitos por corpo editorial serviram de suporte na elaboração do texto final.

\section{Interação dos sistemas imune e endócrino}

O sistema imune tem a capacidade de proteger o organismo contra agentes que possam causar dano tissular ou doença. Esta capacidade de defesa é operacionalizada pelos órgãos linfóides imunes primários, quando células especializadas em promover resposta imunológica na presença de antígenos não-próprios são desenvolvidas. O sistema imune também mantém a memória do primeiro contato, de tal modo que, numa segunda exposição ao mesmo agente externo, haja indução de uma resposta mais acentuada. A imunidade inata, responsável pela resposta imune inicial, envolve barreiras físicas, enzimas, complementos e citocinas em seu componente humoral, e neutrófilos, basófilos, eosinófilos, macrófagos e células matadoras naturais (NK) em seu componente celular. A resposta imune adaptativa humoral opera por anticorpos produzidos pelos linfócitos B e a imunidade adaptativa celular é mediada pelos linfócitos T (supressores ou indutores). Células acessórias e efetoras capazes de destruir agentes não-próprios também podem ser encontradas dentro dos fagócitos ou mesmo em outras células do sistema imunológico ${ }^{6}$. 
A existência de uma interação marcante entre os sistemas imune e endócrino está fundamentada na observação de que (1) as células de ambos os sistemas possuem receptores para citocinas, neurotransmissores e neuropeptídeos, (2) produtos imuno-neuroendócrinos são achados em ambos os tecidos, linfóide e endócrino, (3) mediadores endócrinos podem modular o sistema imune e (4) mediadores imunes podem afetar estruturas do sistema endócrino ${ }^{7}$. Sabe-se que receptores para diferentes hormônios não se manifestam do mesmo modo em todos os tipos de células do sistema imunológico e tanto o número como a atividade destes receptores são dependentes da ativação celular. Células do sistema imune, via receptores, podem ligar prolactina, hormônio de crescimento, corticosteróides, estradiol e testosterona. Por outro lado, receptores para os produtos imunoderivados também são expressos em glândulas endócrinas; assim, receptores para interleucinas são expressos na hipófise, adrenal, ovários, tireóide e pâncreas. Citocinas e pequenos hormônios peptídeos estão, em associação, envolvidos numa ampla variedade de processos imunoinflamatórios ligando os sistemas endócrino, imunológico e neurológico.

O eixo hipotálamo-hipófise-tireóide pode ser inibido pela IL-1, fator de necrose tumoral (TNF) e IL-6. O hormônio tireotrópico aumenta a produção de anticorpos. O hormônio de crescimento induz a proliferação dos linfócitos T e a produção de superóxido aniônico pelos macrófagos. A prolactina (PRL) estimula o sistema imunológico, mas a hiperprolactinemia inibe a função auto-imune. O papel da PRL no sistema imunológico pode ser concentração-dependente. Assim, um nível ótimo de PRL parece ser necessário para a função linfocítica adequada. Tanto os linfócitos $\mathrm{T}$ como os linfócitos B têm receptores para PRL e produzem substância semelhante à PRL, com possível envolvimento na imunomodulação ${ }^{8}$.

O eixo hipotálamo-hipófise-adrenal pode influenciar a função imunológica. Em geral, o hormônio adrenocorticotrópico, os glicocorticóides e os androgênios deprimem a resposta imune in vitro. Por outro lado, as interleucinas podem estimular o eixo hipotálamohipófise-adrenal ${ }^{7}$. O hormônio adrenocarticatrópico pode, por si, inibir a produção de anticorpos e a secreção de linfocinas ou IFN- $\gamma$ pelos linfócitos T. Além disso, sob estresse, os linfócitos perdem sua capacidade de responder aos agentes mitogênicos. O cortisol, em alta concentração, inibe a síntese de anticorpos, a produção de citocinas e a proliferação dos linfócitos. De uma maneira geral, os glicocorticóides suprimem a maturação, diferenciação e proliferação das células imunológicas, atenuando tanto a resposta imune inata como a adquirida ${ }^{9}$. Na resposta inata, os corticosteróides reduzem o número de monócitos circulantes, inibem a secreção de IL-1, IL-6 e TNF- $\alpha$, prejudicando o sistema colagenase, elastase e ativador do plasminogênio tissular. Em adição, glicocorticóides exercem duplo efeito sobre os neutrófilos: afetam a ativação/função e elevam o número total por diminuição da apoptose. Corticóides modificam o padrão da imunidade celular a favor da humoral. Ao diminuir a resposta imune celular, inibem a expressão dos agentes pró-inflamatórios IFN- $\gamma$, IL-2 e TNF- $\beta$, prejudicando a diferenciação dos monócitos em macrófagos, células NK e células citotóxicas T, responsáveis pela fagocitose e destruição dos agentes estranhos. Ao estimular a resposta humoral o corticóide favorece a síntese de citocinas antiinflamatórias (IL-4, IL-10, IL-13), estimulando a diferenciação de eosinófilos, mastócitos e linfócitos B, importantes para a produção de anticorpos de defesa ${ }^{5}$.

O eixo hipotalámo-hipófise-ovariano também pode modular a função imune. O hormônio liberador de gonadotrofinas $(\mathrm{GnRH})$ parece estar implicado tanto no desenvolvimento como na modulação deste sistema ${ }^{10}$. Por outro lado, receptores específicos do GnRH são expressos em monócitos e linfócitos T e $\mathrm{B}^{11}$. O papel fisiológico extra-hipofisário do $\mathrm{GnRH}$ no sistema imunológico é ainda pouco entendido. $\mathrm{O}$ uso de análogos do $\mathrm{GnRH}$ pode aumentar o número de células NK e a atividade mitogênica dos linfócitos T. Considerando como função recíproca, quando administrada centralmente a IL-1 diminui tanto a secreção de GnRH como a do hormônio luteinizante ${ }^{12}$. Tanto em animais de experimentação como em humanos, estradiol e testosterona atenuam a produção das citocinas pró-inflamatórias IL-1, IL-6 e TNF- $\alpha^{2}$.

\section{Efeitos dos esteróides sexuais na resposta imunológica}

Risco maior de mulheres desenvolverem doenças auto-imunes sugere que estas doenças são, de algum modo, mediadas pelos esteróides sexuais. A influência destes esteróides no sistema imune é um processo genômico e exige a existência de receptores apropriados. Estes receptores podem ligar diferentes hormônios ovarianos e adrenais, mas não estão presentes em todos os tipos de células do sistema imunológico. Mulheres têm o timo mais desenvolvido, maiores níveis de imunoglobulinas e maior proporção de linfócitos T CD4/ CD8 na circulação periférica ${ }^{13}$. Por outro lado, as células NK têm menor atividade citotóxica e menor citotoxidade celular dependente de anticorpos ${ }^{14}$. Os esteróides gonadais podem regular o número de monócitos, sua 
produção de citocinas e a diferenciação destes monócitos em macrófagos, exercendo suas funções sobre o sistema imunológico por modificar a secreção das citocinas imunomoduladoras e regular a expressão de receptores na superfície celular. Estes mecanismos influenciam tanto o número como a função celular.

O estrogênio não altera a atividade celular imunossupressora, mas concernente à imunidade humoral, em concentrações fisiológicas, estimula a produção de imunoglobulinas, possivelmente pela inibição dos linfócitos T supressores 5 . Há fortes evidências de que o estrogênio causa mudanças tanto no número total de linfócitos como nos seus diferentes subtipos. In vitro, os estrogênios promovem a proliferação dos linfócitos T, diferenciação, proliferação e sobrevivência dos linfócitos $\mathrm{B}$ e maior produção de imunoglobulinas $\mathrm{IgG}$ e $\operatorname{IgM}^{15}$. O estrogênio também pode suprimir a linfopoiese B, devido à existência de receptor específico nas células do estroma da medula óssea, e aumentar a produção de imunoglobulinas IgG e IgM nos linfócitos B em seres humanos, via maior produção de IL-10 nos monócitos ${ }^{15}$. Além do mais, estudos clínicos têm mostrado que o estrogênio deprime a imunidade celular, suprime a atividade das células $\mathrm{NK}^{15}$, diminui a produção de TNF- $\alpha^{16}$, aumenta a produção de anticorpos e ativa os macrófagos com maior produção de IL-1, IL-4, IL-6, IL-10, INF- $\alpha$ e TNF- $\alpha^{17}$. Nos monócitos humanos, o estradiol diminui os níveis de IL-6 e não altera os níveis de TNF- $\alpha^{18}$.

Os estrogênios facilitam a inibição da proliferação das células mononucleares do sangue periférico (PBMC) em resposta a antígenos não-próprios ${ }^{19}$. $\mathrm{O}$ estradiol também aumenta os antígenos nas células epiteliais uterinas e as concentrações de IgA e IgG nas secreções deste órgão e estimula ainda o mRNA do IFN- $\gamma$ nos linfócitos e a expressão dos receptores desta citocina no endométrio.

A progesterona tem efeito imunossupressor sobre o sistema imunocelular e pode aumentar a atividade dos linfócitos supressores T (CD8). Em baixas concentrações, estimula a secreção de IL- $\alpha$; enquanto em níveis mais elevados, tem uma ação inibitória sobre esta interleucina. A progesterona, em níveis de até $5 \mathrm{ng} / \mathrm{mL}$, aumenta a produção de TNF- $\alpha$ e, em concentrações maiores, inibe a produção desta citocina. Vários estudos demonstram que, durante a gravidez, ocorre supressão do sistema imunocelular para prevenir a rejeição materna fetal, pelo aumento nos níveis de estrogênio e/ou progesterona ${ }^{20}$. Apoio a este papel supressivo da progesterona é dado pelo conhecimento de que muitas doenças auto-imunes, como a artrite reumatóide e a esclerose múltipla, podem melhorar com a gravidez e piorar depois do parto. Nos monócitos humanos, a progesterona eleva a síntese das citocinas pró-inflamatórias TNF- $\alpha$ e IL- $6^{18}$.

Os androgênios são principalmente supressores das imunidades celular e humoral, tendo a capacidade de modificar tanto as ações dos linfócitos $\mathrm{T}$ como dos linfócitos $\mathrm{B}$, além de regular as funções imunocompetentes do linfócito $\mathrm{T}^{20}$. A testosterona não age nas células imunossupressoras. Receptores para a dehidroepiandrosterona (DHEA) foram identificados nos linfócitos T humanos, mas é possível que androgênios fracos atuem apenas após conversão em androgênios ativos ( $\mathrm{T}$ e DHT) ou em estrogênios (estrona, estradiol). Enzimas capazes desta conversão são expressas nos PBMC e macrófagos. A DHEA parece capaz de aumentar a secreção de IL- $2^{21}$, ativar as células NK e inibir a liberação de IL-6 in vitro. No entanto, nenhum benefício sobre a resposta imune foi mostrado com seu uso clínico ${ }^{22}$. Os androgênios, como os estrogênios, podem ainda suprimir a linfopoiese B em conseqüência da presença de receptor específico antagonista androgênico na medula óssea. Via conversão metabólica a estrogênios, os androgênios podem também estimular a resposta imuno-humoral ${ }^{20}$. Em monócitos humanos, a testosterona estimula a síntese da citocina pró-inflamatória IL-6 e não modifica a produção de TNF- $\alpha^{18}$.

\section{Função imune durante o ciclo menstrual}

Tanto a resposta imunológica celular como a humoral podem ser modificadas de acordo com as fases do ciclo menstrual ${ }^{23}$. A fase menstrual está associada com a supressão das células $\mathrm{NK}^{24}$. $\mathrm{Na}$ fase folicular, há um domínio da resposta imunocelular. Durante o período pré-ovulatório, há diminuição na atividade citolítica das células $\mathrm{NK}^{25}$; durante a fase lútea, há uma mudança da resposta imunocelular em direção à humoral. $\mathrm{Na}$ fase lútea média, a progesterona aumenta a produção de IL-1, diminui as concentrações de IL-6, não altera os níveis de IL-10 e diminui a capacidade das células secretoras de inibir o PBMC. Na fase lútea tardia, há também maior produção de IL-1ß e IL-4 e aumento no número de granulócitos, monócitos, linfócitos e no número total de leucócitos circulantes ${ }^{23}$. Nesta fase, a progesterona induz diferenciação celular e modifica a composição/função das células imunes no endométrio. A ação citolítica das células $\mathrm{CD} 3+\mathrm{T}$ é suprimida na fase secretora pela ação da progesterona ${ }^{25}$. Não há nenhuma diferença na porcentagem de distribuição dos subtipos de linfócitos durante qualquer uma das fases do ciclo menstrual, favorecendo a síntese do fator bloqueador induzido pela progesterona ${ }^{26}$. 
Menopausa, hipoestrogenismo e sistema imune

O processo de envelhecimento está associado à diminuição da resistência às infecções, talvez em conseqüência do comprometimento do sistema imune resultante da própria idade. O declínio dos esteróides sexuais tem implicações também nos tecidos não reprodutivos. Logo, níveis baixos de estrogênio, observados em animais castrados ou em mulheres após a menopausa, têm mostrado atenuar a resposta imune e predispor o organismo à invasão microbiana e infecção $0^{27,28}$. Em estudos animais, a retirada dos hormônios sexuais por gonadectomia parece estimular a resposta imune celular e a reposição destes hormônios induz resposta contrária. Em macacas, o hipoestrogenismo reduz a atividade das células NK, eleva a produção de CD8, células $\mathrm{HLA}-\mathrm{DR}+\mathrm{CD} 3+\mathrm{e}$ diminui a proporção de eosinófilos ${ }^{29}$. Mulheres na pósmenopausa têm menor número de células secretoras de citocinas do que na pré-menopausa ${ }^{30}$. A perda da função ovariana com a menopausa está associada ao aumento dos marcadores séricos pró-inflamatórios (IL-1, IL-6, TNF- $\alpha$, selectina-E, moléculas de adesão intracelular ICAM-1) e hiperesponsividade das células do organismo a estas citocinas em conseqüência do aumento no número de receptores e cofatores facilitadores da ação das citocinas ${ }^{29}$. Um estudo de corte transversal relatou diminuição nos números de linfócitos CD4, linfócitos $\mathrm{B}$ e atividade citotóxica das células NK em mulheres após a menopausa ${ }^{31}$. As subpopulações de linfócitos T não diferem em mulheres pré e pós-menopausa ${ }^{32}$.

Níveis baixos de estrogênio e sulfato de DHEA DHEA-S) em mulheres pós-menopausa resultam em diminuição do número de células secretoras de IFN- $\gamma$ e TNF- $\alpha$, contribuindo com o declínio da reatividade imunológica. Uma correlação positiva entre os níveis séricos de estrogênio e a relação CD4:CD8 foi constatada. Após ooforectomia, a porcentagem de linfócitos CD19+, razão CD4+/CD8 + e níveis séricos de IL-4 e IFN- $\gamma$ diminuem ${ }^{33}$. As mulheres com falência ovariana prematura têm diminuição das células NK (CD3-/CD16+1 CD56) e aumento tanto dos linfócitos B (CD19) como dos linfócitos T (CD8+HLA-DR + $)^{34}$. Um aumento significativo nas IL-1 e IL-6 foi também detectado após a menopausa. $\mathrm{Na}$ verdade, vários estudos observaram aumento nos níveis circulantes de IL-6 e TNF- $\alpha$ após a menopausa, tanto natural como cirúrgica ${ }^{34,35}$. Um aumento nas citocinas pró-inflamatórias IL-1, IL-6 e TNF- $\alpha$ e na atividade do fator estimulante de colônias secretadas pelos macrófagos granulócitos (GM-CSF) foi detectado em cultura de monócitos circulantes, osso, macrófagos medulares e osteoblastos na deficiência estrogênica ${ }^{35}$. Estudos clínicos experimentais sugerem a existência de associação entre aumento das citocinas pró-inflamatórias e a perda óssea que segue a menopausa. De fato, a IL-6, forte fator de reabsorção óssea, aumenta após a menopausa ${ }^{36}$.

\section{Efeitos da terapia hormonal após a menopausa na resposta imune}

A terapia com estrogênio (TE) em mulheres após a menopausa é eficiente na atenuação dos sintomas vasomotores, reversão da atrofia genital, inibição da perda da massa óssea e diminuição do risco de fraturas. Efeitos potencialmente benéficos da TE/TH em outros sistemas necessitam maior investigação. Estudos recentes indicam a ocorrência de várias mudanças na resposta imune, tanto após a retirada dos hormônios esteróides sexuais como após sua substituiçãa ${ }^{37,38}$. O hipoestrogenismo nas mulheres após a menopausa pode afetar a resposta imune ${ }^{35}$. Do mesmo modo que a retirada dos estrogênios pode aumentar a liberação das citocinas pró-inflamatórias IL- $1 \beta$, IL-6 e TNF- $\alpha$, a administração de estrogênios pode inibir sua expressão e liberação ${ }^{39}$. Numerosos estudos demonstraram existir plausibilidade biológica entre o uso de esteróides sexuais e os mecanismos moduladores de defesa do organismo em mulheres após a menopausa; no entanto, a eficácia ou não da TH/TE em melhorar estes mecanismos necessita de avaliação crítica dos dados clínicos e epidemiológicos disponíveis.

O efeito da TH/TE sobre a resposta imunocelular em mulheres na pós-menopausa foi avaliado em alguns estudos. Em estudo caso controle recente, as usuárias de estrogênios conjugados mostraram elevação no número total de leucócitos em relação às não usuárias. No entanto, a contagem dos diferentes subtipos de leucócitos foi semelhante nos dois grupos ${ }^{40}$. Manyonda et al. $^{41}$ trataram 15 mulheres com um sistema adesivo contendo $100 \mu \mathrm{g}$ de estradiol, seguido por uma combinação de estrogênio e progestogênio, aplicado duas vezes por semana, como terapia de longo termo. A combinação induziu mudanças significativas nos diferentes tipos de linfócitos e diminuição na hipersensibilidade, quando testada pelas provas de sensibilidade da pele e reação mista de linfócitos, mostrando que o estradiol atenua a resposta inflamatória celular em mulheres após a menopausa. O efeito da TH na imunidade celular foi também avaliado em mulheres na pós-menopausa, sedentárias ou fisicamente ativas, com o objetivo primário de avaliar a influência da atividade física sobre o sistema imunológico ${ }^{42}$. A reatividade mitogênica dos linfócitos no grupo recebendo TH foi 
menor que a observada no grupo não recebendo esta terapia. Houve também tendência para a reatividade linfocitária $\mathrm{T}$ ser maior nas mulheres ativas, quando comparadas com as sedentárias. Não houve nenhuma mudança na atividade celular NK, representativa da imunidade inata do sistema imune. Concluiu-se que o efeito supressivo da TH na função dos linfócitos T em mulheres pós-menopausa pode ser minimizado pelo exercício físico. Estudo posterior observou que a diminuição dos linfócitos T (CD3+CD19) em mulheres pós-menopausa foi maior após a introdução de TH. No entanto, linfócitos T $(\mathrm{CD} 3+\mathrm{CD} 25+$ e CD3+ HLA-DR), com maiores concentrações em mulheres na pós-menopausa, não diminuíram após a TH. Pelo contrário, depois de seis meses de TH, a menor citotoxicidade $\mathrm{NK}$ vista em mulheres após a menopausa eleva-se a um valor semelhante ao observado na prémenopausa ${ }^{32}$. Em um pequeno ensaio clínico controlado, a atividade lítica das células NK e a citotoxidade celular anticorpos-dependente foram analisadas em mulheres pós-menopausa depois de tratamento com estradiol oral ou transdérmico ${ }^{43}$. As mulheres tratadas tiveram diminuição na atividade das células NK logo após três semanas do início do tratamento. Não obstante, as mulheres pós-menopausa ainda apresentaram atividade NK maior do que o grupo controle de mulheres na pré-menopausa. Não houve nenhuma diferença na toxicidade celular anticorpo-dependente entre mulheres pré-menopausa e as pacientes pós-menopausa usuárias de estradiol. Outro estudo controlado mostrou que a TH favorece a proliferação dos linfócitos e atenua a citotoxidade natural mediada pelos leucócitos ${ }^{44}$. Em adição, a TH mostrou reversão nas alterações imunológicas associadas ao envelhecimento. Assim, a TH aumenta o número dos linfócitos $\mathrm{B}$, a atividade mitótica dos linfócitos T e o TNF- $\alpha$, com preservação ou melhora da função imunológica. Estudo mais recente confirmou diminuição da atividade citotóxica das células NK em mulheres em $\mathrm{TH}^{45}$. Como as células NK constituem primeira linha na defesa contra infecção viral e inibição de crescimento tumoral e os estudos sobre a TH e atividade das células NK são ainda escassos ou inconsistentes, maiores ensaios clínicos são necessários para avaliar a possível repercussão negativa da TH/TE nestas duas condições clínicas.

Em síntese, 14 estudos, que foram publicados entre 1992 e 2006, examinaram os efeitos da TH sobre a resposta imune celular em mulheres após a menopausa. Todos incluíram pequeno número de mulheres e investigaram o efeito do estrogênio oral ou transdérmico associado ou não ao acetato de medroxiprogesterona ou noretisterona por tempo inferior a seis meses.
Apenas um estudo incluiu usuárias de TH por mais de 12 meses $^{46}$ e três compararam TH com placebo ${ }^{43,44,46}$. A proliferação dos linfócitos, examinada em estudo isolado pela reação mista linfocitária e sensibilidade dérmica a múltiplos antígenos, foi precocemente atenuada com o uso de estradiol transdérmico ${ }^{41}$. Tanto diminuição $0^{41,44}$ como elevação ${ }^{32,40}$ ou nenhuma modificação do número total de leucócitos ${ }^{46}$ ou da citotoxidade das células NK foram documentadas após TH combinada. Quatro estudos demonstraram diminuição da produção das citocinas relacionadas à imunidade celular na resposta inflamatória (IL-2, INF- $\gamma)^{33,34,45,47}$. Elevação do IFN- $\alpha$ foi documentada em um único estudo ${ }^{46}$. No conjunto, estes estudos indicam que a $\mathrm{TH}$ melhora ou resgata a resposta imune celular afetada após a menopausa.

Modificações na imunidade humoral foram também observadas após a menopausa. O efeito da TH tem sido também estudado neste tipo de imunidade. Em resumo, 12 estudos, publicados entre 1989 e 2006, examinaram o efeito da TH sobre a resposta imune humoral em mulheres após a menopausa. Apenas um deles examinou o efeito da TH sobre os níveis das imunoglobulinas e complemento ${ }^{47}$. Todos os outros examinaram a imunidade humoral indiretamente pela dosagem das citocinas tipo II (IL-1 $\beta$, IL-4, IL-5, IL-6 e IL-10) auxiliares no desenvolvimento e manutenção da resposta imune humoral. Diminuição da IL-6 e nenhuma mudança significativa nos níveis de IL-4, IL-10 e INF- $\gamma$ foram inicialmente relatadas em estudo prospectivo após três meses de terapia estrogênica ${ }^{48}$. Elevação nos níveis de IL-6 foi observada com o uso de estrogênio após seis semanas ou terapia estroprogesterônica por um ano ${ }^{38,46}$. Tanto diminuiçãa ${ }^{38,47,49}$ como nenhuma alteração ${ }^{50}$ na produção de IL-10 foram relatadas. Tanto na menopausa precoce quanto na oportuna, a TH mostrou-se capaz de aumentar os níveis de GM-CSF sem induzir mudanças nos níveis de TGF- $\beta$, TNF- $\alpha$, GM-CSF e IL-18. Em estudo de corte-transversal, foi mostrado que os níveis médios de C3 e C4 estão elevados nas usuárias de TH, seja em uso oral ou transdérmico ${ }^{51}$.

Os efeitos da TH sobre os marcadores de inflamação em mulheres pós-menopausa permanecem em intensa avaliação, principalmente no sistema cardiovascular. $\mathrm{O}$ estrogênio parece tanto estimular como inibir os processos inflamatórios. Por um lado, reduz os níveis plasmáticos das moléculas de adesão vascular solúveis (sICDM-1, sVCAM-1), selectina e proteína-1 quimioatrativa de monócitos (MPC-1), sugerindo uma ação anti-inflamatória na parede vascular ${ }^{52}$. Em adição, a TH inibe a produção de fatores pró-coagulantes nos monócitos circulantes. Por outro lado, o uso de TE mostrou-se capaz de aumentar os níveis de proteína $C$ reativa (PCR) circulante, um 
componente da fase aguda da resposta inflamatória ${ }^{53}$. Efeito semelhante foi observado com o uso de estrogênios conjugados em outros estudos ${ }^{54}$. Em estudo clínico randomizado realizado em mulheres histerectomizadas, a elevação da PCR observada no início do tratamento sofreu reversão após 24 meses de uso, sugerindo a possibilidade de que o efeito pró-inflamatório seja temporário ${ }^{55}$. A via de administração do estrogênio parece exercer efeitos diferentes sobre as concentrações de PCR e proteína sérica amilóide A (SAA). A SAA tem seus níveis reduzidos com a via transdérmica e elevados na oral. A elevação de PCR também ocorre principalmente com a via oral ${ }^{56}$. Embora os mecanismos não sejam claros, parece que a elevação da PCR e SAA com a via oral resulta da ativação da produção de IL-6 pró-inflamatória, via maior produção hepática. A maioria dos estudos observacionais e randomizados tem demonstrado que a TE transdérmica diminui ou não altera os níveis séricos de IL-1, IL-6, e TNF- $\alpha^{57}$. O tema foi recentemente explorado em estudo caso-controle (Estudo Observational de Iniciativa de Saúde das Mulheres - WHOS), comparando os níveis de IL-6 pró-inflamatória em usuárias e não usuárias de TH. Neste estudo, os níveis de IL-6 foram semelhantes - ou ligeiramente menores - nas usuárias, quando comparadas com as não-usuárias, sugerindo que a $\mathrm{TH}$ inibe a resposta inflamatória ${ }^{57}$.

A administração combinada estroprogestogênica, atenuante da resposta inflamatória em estudos experimentais, parece não inibir as proteínas VCAM-1, ICAM-1 ou MPC-1 pró-inflamatórias em mulheres após a menopausa ${ }^{58}$. A adição de progesterona ou medroxiprogesterona não impede o efeito protetor do estradiol na diminuição destas proteínas e parece mesmo capaz de reduzi-las ainda mais ${ }^{59}$. Enquanto a $\mathrm{TH}$ associando estrogênio a acetato de medroxiprogesterona, desogestrel ou noretisterona eleva a PCR, a associação estrogênioacetato de norgestrel parece reduzir a síntese desta proteína $^{60,61}$. Em adição, a associação da noretisterona ao estradiol nasal também não foi associada à elevação da PCR e manteve a diminuição das moléculas de adesão ${ }^{52}$. No conjunto, estes estudos sugerem que o tipo do progestogênio utilizado tem relevância na resposta imuno humoral.

\section{Conclusão}

Os esteróides sexuais parecem ter um papel importante na regulação do sistema imune. Nesta ação, o efeito destes esteróides deve ser visto num contexto imunoendócrino, no qual interação bidirecional entre os sistemas endócrino e imune pode ocorrer. As mulheres na pós-menopausa podem ter respostas imunes anormais e uma maior tendência às infecções. Enquanto o hipoestrogenismo favorece a liberação de citocinas pró-inflamatórias, o estrogênio exerce efeito oposto. Estudos epidemiológicos e clínicos indicam normalização da resposta imunocelular com a TE/TH após a menopausa. Os efeitos desta terapia sobre a imunidade humoral são ainda inconsistentes. A terapia não-oral, por não modificar as citocinas pró-inflamatórias, a PCR e as proteínas de adesão vascular, mostra efeito anti-inflamatório. O papel de cada componente esteróide, sua via de administração, dose e tempo de uso necessitam maior investigação. Os resultados atuais devem ser considerados preliminares. Ainda que haja plausibilidade biológica para o efeito benéfico da TE/ TH sobre a imunidade na pós-menopausa, estudos adicionais devem ser efetuados antes que qualquer conclusão sobre eficácia clínica possa ser retirada.

\section{Agradecimentos}

À Fundação de Apoio à Pesquisa do estado de Mato Grosso - Fapemat, pelo suporte financeiro.

\section{Referências}

1. Medeiros SF, Medeiros MMWY, Oliveira VN. Climacteric complaints among very low-income women from a tropical region of Brazil. São Paulo Med J. 2006;124(4):214-8.

2. Miller RA. The aging immune system: primer and prospectus. Science. 1996;273(5271):70-4

3. Straub RH, Cutolo M, Zietz B, Scholmerich J. The process of aging changes the interplay of the immune, endocrine and nervous systems. Mech Ageing Dev. 2001;122(14):1591-611.

4. Kishimoto S, Tomino S, Mitsuya H, Nishimura H. Age-related decrease in frequencies of B-cell precursors and specific helper $T$ cells involved in the $\lg G$ anti-tetanus toxoid antibody production in humans. Clin Immunol Immunopathol. 1982;25(1):1-10.
5. Grossman CJ, Rossele GA, Mendenhall CL. Sex steroid regulation of autoimmunity. J Steroid Biochem Mol Biol. 1994;40(4-6):649-59.

6. Beagley KW, Gockel CM. Regulation of innate and adaptive immunity by the female sex hormones oestradiol and progesterone. FEMS Immunol Med Microbiol. 2003;38(1):13-22.

7. Basedovsky HO, Del Rey A. Immune-neuro-endocrine interactions: facts and hypotheses. Endocr Rev. 1996;17(1):64-102.

8. Russell DH. New aspects of prolactin and immunity: a lymphocytederived prolactin-like product and nuclear protein kinase C activation. Trends Pharmacol Sci. 1989;10(1):40-4.

9. Webster Jl, Tonelli L, Sternberg EM. Neuroendocrine regulation of immunity. Annu Rev Immunol. 2002;20:125-63. 
10. Ho HN, Wu MY, Chen HF, Chao KH, Yang YS, Huang SC, et al. In vivo $C D 3+C D 25+$ lymphocyte subpopulation is down-regulated without increased serum-soluble interleukin-2 receptor (sIL-2R) by gonadotropin releasing hormone agonist $(\mathrm{GnRH}-\mathrm{a})$. Am J Reprod Immunol. 1995;33(1):134-9.

11. Silveira LF, Stewart PM, Thomas M, Clark DA, Bouloux PM, MacColl GS. Novel homozygous splice acceptor site $\mathrm{GnRH}$ receptor (GnRHR) mutation: human GnRHR 'knockout'. J Clin Endocrinol Metab. 2002;87(6):2973-7.

12. Rivest $S$, Rivier $C$. The role of corticotropin-releasing factor and interleukin- 1 in the regulation of neurons controlling reproductive function. Endocr Rev. 1995; 16(2): 177-99.

13. Amadori A, Zamarchi R, De Silvestro G, Forza G, Cavatton G, Danieli GA, et al. Genetic control of the CD4/CD8 T-cell ratio in humans. Nat Med. 1995;1(12):1279-83.

14. Pelfrey CM. Sexual dimorphism in autoimmunity: a focus on Th1/ Th2 cytokines and multiple sclerosis. Clin Appl Immunol Rev. $2001 ; 1(6): 331-45$.

15. Kanda N, Tamaki K. Estrogen enhances immunoglobulin production by human PBMCs. J Allergy Clin Immunol. 1999;103(2 Pt 1):282-8

16. Hong SC, Yoo SW, Cho GJ, Kim T, Hur JY, Park YK, et al. Correlation between estrogens and serum adipocytokines in premenopausal and postmenopausal women. Menopause. 2007;14(5):835-40.

17. DeLoia J, Stewart-Akers AM, Brekosky J, Kubik CJ. Effects of exogenous estrogen on uterine leukocyte recruitment. Fertil Steril. 2002;77(3):548-54.

18. Jain SK, Kannan K, Prouty L, Jain SK. Progesterone, but not 17 $\beta$ estradiol, increases TNF- $\alpha$ secretion in U937 monocytes. Cytokine. 2004;26(3): 102-5.

19. Prabhala RH, Fahey JV, Humphrey SL, Edkins RD, Stern JE, Wira CR. Regulation by human uterine cells of PBMC proliferation: influence of the phase of the menstrual cycle and menopause. J Reprod Immunol. 1998;40(1):25-45.

20. Grossman CJ. Regulation of the immune system by sex steroids. Endocr Rev. 1984;5(3):435-55.

21. Luchetti CG, Solano ME, Sander V, Arcos ML, Gonzalez C, Di Girolamo $G$, et al. Effects of dehydroepiandrosterone on ovarian cystogenesis and immune function. J Reprod Immunol. 2004;64(12):59-74.

22. Arlt $W$, Hewison $M$. Hormones and immune function: implications of aging. Aging Cell. 2004;3(4):209-16.

23. Faas $M$, Bouman $A$, Moes $H$, Heineman M, de Leij L, Schuiling $G$. The immune response during the luteal phase of the ovarian cycle: a Th2-type response? Fertil Steril. 2000;74(5): 1008-13.

24. Shakhar K, Shakhar G, Rosenne E, Ben-Eliyahu S. Timing within the menstrual cycle, sex, and the use of oral contraceptives determine adrenergic suppression of NK cell activity. $\mathrm{Br} J$ Cancer. 2000;83(12): 1630-6.

25. White HD, Crassi KM, Givan AL, Stern JE, Gonzalez JL, Memoli VA, et al. $C D 3+C D 8+C T L$ activity within the human female reproductive tract: influence of stage of menstrual cycle and menopause. J Immunol. 1997; 158(6):3017-27.

26. Szekeres-Bartho J, Wegmann TG. A progesterone-dependent immunomodulatory protein alters the Th1/Th2 balance. J Reprod Immunol. 1996;31(1):81-95.

27. Olsen NJ, Kovacs WJ. Gonadal steroids and immunity. Endocr Rev. 1996;17(4):369-84.

28. Medeiros SF, Oliveira VN, Yamamoto MMW. Epidemiologia clínica do climatério. Reprod Clim. 2003;18(1):79-86.
29. Keller ET, Zhang J, Yao Z, Qi Y. The impact of chronic estrogen deprivation on immunologic parameters in the ovariectomized rhesus monkey (Macaca mulatta) model of menopause. J Reprod Immunol. 2001;50(1):41-55.

30. Verthelyi D, Klinman DM. Sex hormone levels correlate with the activity of cytokine-secreting cells in vivo. Immunology. 2000;100(3):384-90.

31. Giglio T, Imro MA, Filaci G, Scudeletti M, Puppo F, De Cecco $L$, et al. Immune cell circulating subsets are affected by gonadal function. Life Sci. 1994;54(18):1305-12.

32. Yang JH, Chen CD, Wu MY, Chao KH, Yang YS, Ho HN. Hormone replacement therapy reverses the decrease in natural killer cytotoxicity but does not reverse the decreases in the T-cell subpopulation or interferon-gamma production in postmenopausal women. Fertil Steril. 2000;74(2):261-7.

33. Kumru S, Godekmerdan A, Yilmaz B. Immune effects of surgical menopause and estrogen replacement therapy in peri-menopausal women. J Reprod Immunol. 2004;63(1):31-8.

34. Kamada $M$, Irahara $M$, Maegawa $M$, Ohmoto $Y$, Takeji T, Yasui $T$, et al. Postmenopausal changes in serum cytokine levels and hormone replacement therapy. Am J Obstet Gynecol. 2001;184(3):309-14.

35. Yasui T, Maegawa M, Tomita J, Miyatani Y, Yamada M, Uemura H, et al. Changes in serum cytokine concentrations during the menopausal transition. Maturitas. 2007;56(4):396-403.

36. Pfeilschiffer J, Koditz R, Pfohl M, Schatz H. Changes in proinflammatory cytokine activity after menopause. Endocr Rev. 2002;23(1):90-1 19.

37. Straub RH, Hense HW, Andus T, Scholmerich J, Riegger GA, Schunkert $\mathrm{H}$. Hormone replacement therapy and interrelation between serum interleukin- 6 and body mass index in postmenopausal women: a population-based study. J Clin Endocrinol Metab. 2000;85(3):1340-4.

38. Brooks-Asplund EM, Tupper CE, Daun JM, Kenney WL, Cannon JG. Hormonal modulation of interleukin-6, tumor necrosis factor and associated receptor secretion in postmenopausal women. Cytokine. 2002; 19(4): 193-200.

39. Morishita $M$, Miyagi $M$, Iwamoto $Y$. Effects of sex hormones on production of interleukin-1 by human peripheral monocytes. J Periodontol. 1999;70(7):757-60.

40. Medeiros SF, Nince APB. Efeito da terapia de reposição hormonal sobre o sistema imune no climatério. Anais do XII Encontro de Iniciação Científica da UFMT; 15-16 jul 2004; Cuiabá; 2004. p. 269.

41. Manyonda IT, Pereira RS, Makinde V, Brincat M, Varma RT. Effect of $17 \beta$-oestradiol on lymphocyte subpopulations, delayed cutaneous hypersensitivity responses and mixed lymphocyte reactions in postmenopausal women. Maturitas. 1992;14(3):201-10.

42. Hough HJ, Failla ML, Ludwig DA. Active lifestyle offsets HRTinduced suppression of T cell reactivity to mitogens. Maturitas. 1999;33(3):211-8.

43. Albrecht AE, Hartmann BW, Scholten C, Huber JC, Kalinowska W, Zielinski CC. Effect of estrogen replacement therapy on natural killer cell activity in postmenopausal women. Maturitas. 1996;25(3):217-22

44. Fahlman MM, Boardley D, Flynn MG, Bouillon LE, Lambert $C P$, Braun WA. Effects of hormone replacement therapy on selected indices of immune function in postmenopausal women. Gynecol Obst Invest. 2000;50(3):189-93.

45. Stopinska-Gluszak U, Waligóra J, Grzela T, Gluszak M, Jozwiak J, Radomski D, et al. Effect of estrogen/progesterone hormone replacement therapy on natural killer cell cytotoxicity and immunoregulatory cytokine release by peripheral blood mononuclear cells of postmenopausal women. J Reprod Immunol. 2006;69(1):65-75. 
46. Porter VR, Greendale GA, Schocken M, Zhu X, Effros RB. Immune effects of hormone replacement therapy in post-menopausal women. Exp Gerontol. 2001;36(2):311-26.

47. Deguchi K, Kamada M, Irahara M, Maegawa M, Yamamoto S, Ohmoto $Y$, et al. Postmenopausal changes in production of type 1 and type 2 cytokines and the effects of hormone replacement therapy. Menopause. $2001 ; 8(4): 266-73$.

48. Reuben DB, Palla SL, Hu P, Reboussin BA, Crandall C, Herrington DM, et al. Progestins affect mechanism of estrogen-induced C-reactive protein stimulation. Am J Med. 2006; $119(2): 167$. e 1-8.

49. Rogers A, Eastell R. Effects of estrogen therapy of postmenopausal women on cytokines measured in peripheral blood. J Bone Mineral Res. 1998;13(10):1577-86.

50. Berg G, Ekerfelt C, Hammar M, Lindgren R, Matthiesen L, Ernerudh J. Cytokine changes in postmenopausal women treated with estrogens: a placebo-controlled study. Am J Reprod Immunol. 2002;48(2):63-9.

51. Yilmazer M, Fenkci V, Fenkci S, Aktepe O, Sonmezer M, Kurtay $G$. Association of serum complement $(C 3, C 4)$ and immunoglobulin (lgG, $\lg M$ ) levels with hormone replacement therapy in healthy post-menopausal women. Hum Reprod. 2003; 18(7):1531-5.

52. Christodoulakos GE, Lambrinoudaki IV, Economou EV, Papadias C, Vitoratos N, Panoulis $C P$, et al. Circulating chemoattractants RANTES, negatively related to endogenous androgens, and MCP-1 are differentially suppressed by hormone therapy and raloxifene. Atherosclerosis. 2007;193(1): 142-50.

53. Stanczyk FZ. Parenteral versus oral treatment of postmenopausal women with estrogen. Menopause. 2007 Sep 25 [Epub ahead of print]
54. Hu P, Greendale GA, Palla SL, Reboussin BA, Herrington DM, Barrett-Connor $E$, et al. The effects of hormone therapy on the markers of inflammation and endothelial function and plasma matrix metalloproteinase-9 level in postmenopausal women: the postmenopausal estrogen progestin intervention (PEPI) trial. Atherosclerosis. 2006;185(2):347-52.

55. de Valk-de Roo GW, Stehouwer CD, Meijer P, Mijatovic V, Kluft $C$, Kenemans $\mathrm{P}$, et al. Both raloxifene and estrogen reduce major cardiovascular risk factors in healthy postmenopausal women: a 2-years, placebo-controlled study. Arterioscler Thromb Vasc Biol. 1999; 19(12):2993-3000.

56. Abbas A, Fadel PJ, Wang Z, Arbique D, Jialal I, Vongpatanasin $W$. Contrasting effects of oral versus transdermal estrogen on serum amyloid A (SAA) and high-density lipoproteins: SAA in postmenopausal women. Arterioscler Tromb Vasc Biol. 2004;24(10):e164-7.

57. Pradhan AD, Manson JE, Rossouw JE, Siscovick DS, Mouton CP, Rifai $\mathrm{N}$, et al. Inflammatory biomarkers, hormone replacement therapy, and incident coronary heart disease: prospective analysis from the Women's Health Initiative Observational Study. JAMA. 2002;288(8):980-7.

58. Wakatsuki A, Okatani Y, lkenoue N, Fukaya T. Effect of medroxyprogesterone acetate on vascular inflammatory markers in postmenopausal women receiving estrogen. Circulation. 2002; 105(12): 1436-9.

59. Menon DV, Vongpatanasin W. Effects of transdermal estrogen replacement therapy on cardiovascular risk factors. Treat Endocrinol. 2006;5(1):37-51

60. Gol M, Akan P, Dogan E, Karas C, Saygili U, Posaci C. Effects of estrogen, raloxifene, and hormone replacement therapy on serum C-reactive protein and homocysteine levels. Maturitas. 2006;53(3):252-9.

61. Kwok S, Charlton-Menys V, Pemberton P, McElduff P, Durrington PN. Effects of dydrogesterone and norethisterone, in combination with oestradiol, on lipoproteins and inflammatory markers in postmenopausal women. Maturitas. 2006;53(4):439-46. 